\title{
Circadian Metabolomics: Insights for Biology and Medicine
}

\author{
Steven A. Brown and Ludmila Gaspar
}

\begin{abstract}
A biological "circadian" clock governs nearly all aspects of mammalian behavior and physiology. This control extends from activities of entire organ systems down to individual cells, all of which contain autonomous molecular clocks. Under this control, a significant fraction of the cellular metabolome-the collection of all small-molecule metabolites-varies in abundance according to time of day. Comparing the rhythmic expression of transcripts, proteins, and metabolites has yielded valuable insights into clock-controlled physiological mechanisms. In the future, their analysis could provide a glimpse of instantaneous clock phase, even providing notions of clock time based upon molecules within a single breath. Such knowledge could be important for disease diagnosis and for chronopharmacology.
\end{abstract}

\section{Introduction: A Many-Clock Problem}

A "master clock" tissue in mammals has been identified in the suprachiasmatic nuclei (SCN) of the hypothalamus, about 20,000 neurons distributed into bilateral nuclei just above the optic chiasma. Lesioning of this region results in loss of circadian behavior and physiology under constant environmental conditions (Eastman et al. 1984), and transplantation results in circadian behavior corresponding to that of the donor animal (Ralph et al. 1990). Although the SCN directs circadian timing, the circuitry of which circadian clocks are composed is in fact much more widespread: nearly every cell in the body contains an autonomous molecular oscillator driven by feedback loops of transcription and translation of dedicated "core clock" proteins (Brown and Azzi 2013). Therefore, circadian control of complex physiology is at least in part a question of orchestration: on the one hand, circadian signals from the SCN must synchronize peripheral oscillators

\footnotetext{
S.A. Brown $(\bowtie) \cdot$ L. Gaspar

Chronobiology and Sleep Research Group, Institute of Pharmacology and Toxicology,

University of Zürich, Winterthurerstrasse 190, 8057 Zürich, Switzerland

e-mail: steven.brown@pharma.uzh.ch

P. Sassone-Corsi, Y. Christen (eds.), A Time for Metabolism and Hormones,

Research and Perspectives in Endocrine Interactions,

DOI 10.1007/978-3-319-27069-2_9
} 
elsewhere in the brain and body and, on the other, peripheral clocks must themselves direct circadian processes at a cellular level.

The ultimate consequences of this pervasive circadian control are that, in most mammalian tissues, 6-20\% of all transcripts and proteins are expressed in circadian fashion, i.e., with higher expression at one time of day and lower expression at another (Panda et al. 2002; Storch et al. 2002; Reddy et al. 2006; Robles et al. 2014). It is therefore not surprising that about $20 \%$ of the mammalian metabolome shows circadian variation in both mice and men (Minami et al. 2009; Dallmann et al. 2012; Eckel-Mahan et al. 2012). Given the lower complexity of the metabolome and its extremely high conservation across species compared to the genome, an increasing number of studies have turned to metabolomics analyses to understand circadian biology.

Normally, circadian clocks throughout the body remain in relative synchrony with defined phase relationships. However, during timing shifts provoked by travel and shiftwork, in pathological cases such as inflammation and disease, or even due to the abnormal timing of food intake, this synchrony can be disrupted. For example, if normally nocturnal rodents are fed only during the day, clock phase in peripheral organs like liver and heart will change phase by nearly $12 \mathrm{~h}$, while the SCN remains unaltered (Damiola et al. 2000; Stokkan et al. 2001). On the other hand, during a sudden change in light timing, the SCN will quickly alter its phase whereas peripheral organs require multiple days to do so (Davidson et al. 2009). Disease-mediated inflammation provides another example of peripheral clock dampening or dephasing: in response to infection, the circadian amplitude of transcription for multiple clock and clock-controlled genes decreases markedly (Cavadini et al. 2007). Finally, in both brain and peripheral tissues, sleep-related cellular signals can conflict with clock-related ones, leading to a dampening of circadian amplitude of clock-controlled genes (Maret et al. 2007; Moller-Levet et al. 2013; Archer et al. 2014). Both immediate and long-term consequences of such "clock desynchrony" are only beginning to be understood. For example, circadian amplitude in human subjects is directly correlated with survival time in some cancers (Innominato et al. 2012), and multiple studies in both humans and animals have linked shiftwork to increased disease and mortality (Viswanathan and Schernhammer 2009; Evans and Davidson 2013). As we discuss further below, metabolomics analyses could provide a powerful tool to study circadian phase and amplitude in both humans and animal models, potentially linking these parameters to human health in a wide variety of contexts.

\section{An Overview of Circadian Metabolomics}

Typically, comprehensive metabolomics analyses are conducted by flow injection mass spectrometry. Thus, in a single assay lasting a few seconds, thousands of peaks corresponding to individual metabolites can be detected. At the moment, a significant limiting factor for these studies is the identification of the metabolites 
corresponding to each peak. Most commercially accessible platforms can discretely identify a few hundred different substances, including lipids, amino acids, sugars, enzymatic cofactors, and peptides and hormones. In at least one study, these circadian metabolites have been compared to circadian transcripts in the same tissues in rodents, allowing a direct and comprehensive look at cellular pathways regulated in circadian fashion (Eckel-Mahan et al. 2012).

From this study, it was clear that the circadian clock exerts coordinated control over a large number of metabolic pathways, including those controlling the abundance of lipids, carbohydrates, and amino acids. Of course, given that food is itself consumed in time-of-day-dependent fashion, it would be formally possible that these variations could be indirect consequences of rhythmic activity, rather than direct clock control. In mice, for example, without rhythmic feeding only a small percentage of circadian transcripts continued to show diurnal oscillations (Vollmers et al. 2009). In humans, however, a very different picture has emerged. By analyzing metabolomics parameters from saliva and blood taken from humans kept in a "constant routine" of immobile reclined posture, hourly isocaloric meals, and sleep deprivation, Dallmann et al. (2012) could definitively rule out food-dependent control: $17 \%$ of metabolites in both matrices were rhythmic even in the absence of rhythmic feeding, sleep, and activity (Fig. 1). These included lipids, carbohydrates, and amino acids, the same pathways that demonstrated metabolic control in mice (Eckel-Mahan et al. 2012). The same study also showed that the abundance of some metabolites increased or decreased monotonically with sleep deprivation, implying that sleep pressure and circadian influences might independently regulate diurnal metabolic physiology.

\section{Metabolomics: Applications for Circadian Medicine}

Because various circadian metabolites show peak abundance at different times of day, it is possible to use these relative quantities as indicators of timing. The idea is analogous to the "chronological garden" of the Swedish botanist Carl Linnaeus, who used plants flowering at different times of day to determine geological time at any moment. In precisely the same fashion, Minami et al. (2009) used blood metabolites from mice as a way of detecting circadian body time, and MartinezLozano Sinues et al. (2014) used metabolites within human breath. While potentially quite powerful, these molecular timetable-based methods are hampered by the high inter-individual variability of metabolite abundance among different subjects, making single-time-point analyses relatively imprecise. So far, an accuracy of about $2 \mathrm{~h}$ in circadian time is the best that has been attained. As more individuals are metabolomically characterized into different endophenotypic subtypes, it is likely that this accuracy will increase substantially.

Major applications of such technology would be twofold. First and most simply, it would be possible to determine human body time prior to clinical intervention. For most drugs, both pharmacokinetics and pharmacodynamics vary in circadian 

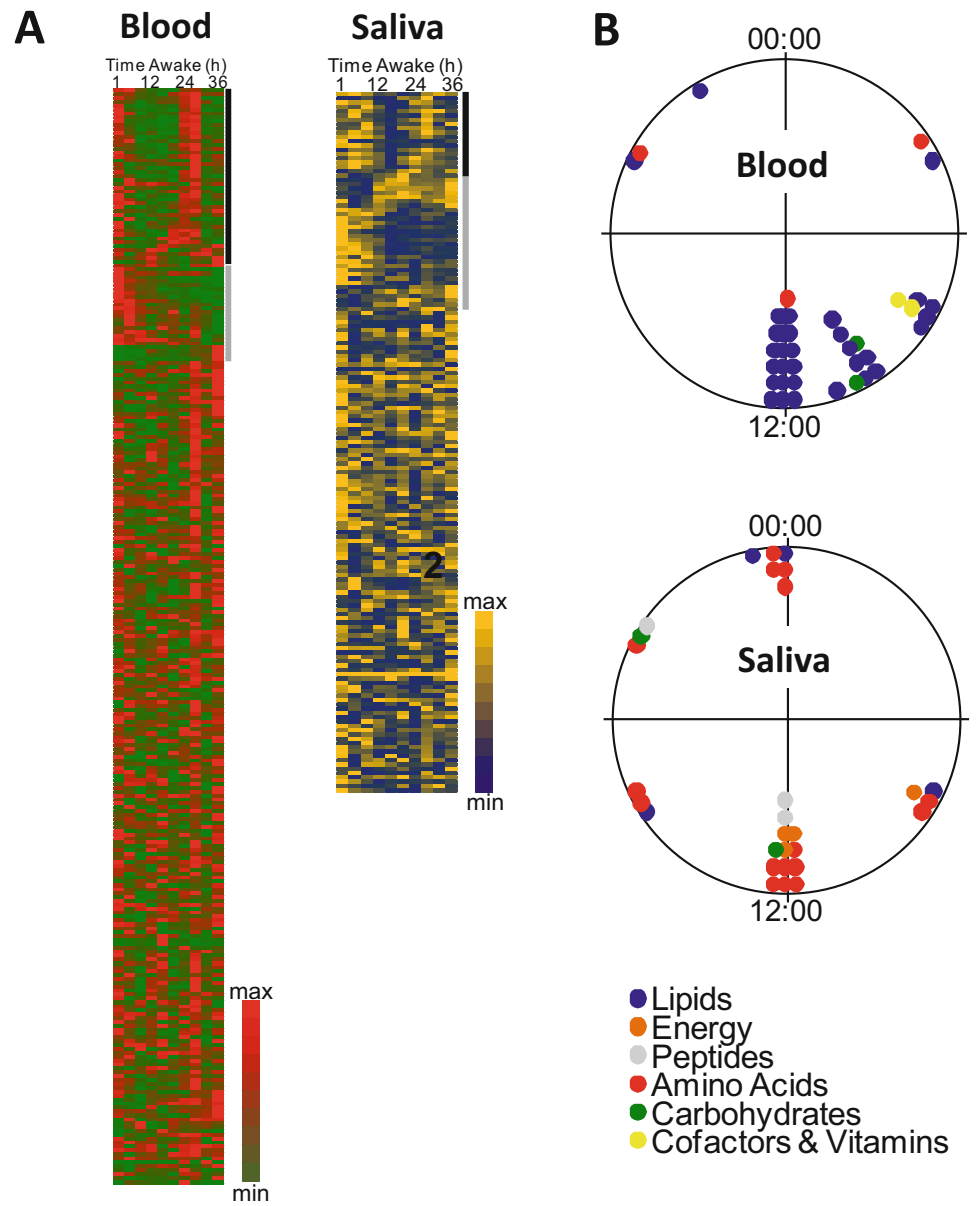

Fig. 1 (a) Heat map of circadian metabolites identified in human blood (left) and saliva (right) from subjects maintained in a constant routine of hourly isocaloric meals, immobile posture, constant dim light, and sleep deprivation. Rows: individual metabolites; columns: time relative to start of experiment. (b) Major classes of compounds identified in blood (top) and saliva (bottom), plotted in circadian time relative to theoretical dawn (Adapted from Dallmann et al. 2012)

fashion. In other words, not only is the metabolism of many xenobiotic substances strongly regulated but also the biological targets of the drugs themselves (Dallmann et al. 2014). Thus, potentially both increased efficacy and reduced toxicity could be obtained by precise timing of delivery, at least in the case of unstable compounds. Currently, multiple clinical trials have been run or are running, especially in the field of cancer, to test this concept (Innominato et al. 2014). Since cell division has been shown to be coordinated with circadian clock timing in both adult animals and cells (Matsuo et al. 2003; Nagoshi et al. 2004; Kowalska et al. 2013; Bieler et al. 2014; Feillet et al. 2014), and many chemotherapeutic agents are metabolized 
by circadian isoforms of cytochrome $\mathrm{P} 450$ in the liver, it is logical to imagine that chemotherapeutic toxicity would itself be circadian. This concept has been demonstrated experimentally in mice (Gorbacheva et al. 2005), and human trials have also shown time-of-day-dependent effects (Innominato et al. 2014).

Secondly, metabolite timetable-based methods would be able to predict not only clock phase but also clock amplitude and possibly even circadian desynchrony. These parameters have been increasingly linked to disease both in humans and in animal models, as mentioned in the introduction, leading the World Health Organization to classify shiftwork as a suspected carcinogen. Even a simple indicator like the amplitude of circadian behavior correlates directly with survival during chemotherapy of metastatic colon carcinoma in humans (Innominato et al. 2012).

It is suspected that one of the main deleterious effects of shiftwork is circadian desynchrony among different organs. In mice, changes in daylight timing shift different organs at different speeds (Davidson et al. 2009). Potentially, metabolomics could give insight into this phenomenon, since various circadian components come from different tissues. For example, the hormone melatonin is secreted by the pineal gland of the hypothalamus and is thought to be a direct output of the SCN. By contrast, many other endocrine factors and metabolites detectable in blood or in breath arise primarily as byproducts of peripheral organ function (Gamble et al. 2014). Therefore, we propose that circadian metabolomics could be useful in elucidating desynchrony between clocks in brain and in other peripheral tissues. To date, no studies have used metabolomics methods in this fashion, but great potential exists.

\section{Outlook and Conclusion}

Questions of circadian desynchrony in health and disease are only beginning to be addressed. The idea that shiftwork might affect circadian clock function is easy to see. However, many other factors could play important and unsuspected roles. For example, recent studies have suggested that chronic sleep restriction alone, even without changed diurnal patterns of activity, could also disrupt circadian transcription (Moller-Levet et al. 2013). Similarly, depressive and affective disorders have long been known to be accompanied by dramatically different sleep-wake patterns (Lamont et al. 2007). Recent research has established a close tie between circadian dysfunction and metabolic disorders like obesity and diabetes (Maury et al. 2014). All of these syndromes are potentially explorable by circadian metabolomics. The conclusions that such studies might derive could both answer outstanding questions about circadian biology and improve human health.

Acknowledgments The research of SAB is supported by the Swiss National Science Foundation, the Velux Foundation, the Swiss Cancer League, and the Zürich Clinical Research Priority Project "Sleep and Health." He is a member of the Zürich Neurozentrum (ZNZ) and Molecular Life Sciences graduate programs within the Life Sciences Zürich Graduate School. LC is a member of 
the ZNZ and has received support from the Zürich Clinical Research Priority Project "Sleep and Health".

Open Access This chapter is distributed under the terms of the Creative Commons AttributionNoncommercial 2.5 License (http://creativecommons.org/licenses/by-nc/2.5/) which permits any noncommercial use, distribution, and reproduction in any medium, provided the original author(s) and source are credited.

The images or other third party material in this chapter are included in the work's Creative Commons license, unless indicated otherwise in the credit line; if such material is not included in the work's Creative Commons license and the respective action is not permitted by statutory regulation, users will need to obtain permission from the license holder to duplicate, adapt or reproduce the material.

\section{References}

Archer SN, Laing EE, Moller-Levet CS, van der Veen DR, Bucca G, Lazar AS, Santhi N, Slak A, Kabiljo R, von Schantz M, Smith CP, Dijk DJ (2014) Mistimed sleep disrupts circadian regulation of the human transcriptome. Proc Natl Acad Sci U S A 111:E682-E691

Bieler J, Cannavo R, Gustafson K, Gobet C, Gatfield D, Naef F (2014) Robust synchronization of coupled circadian and cell cycle oscillators in single mammalian cells. Mol Syst Biol 10:739

Brown SA, Azzi A (2013) Peripheral circadian oscillators in mammals. Handb Exp Pharmacol 217:45-66

Cavadini G, Petrzilka S, Kohler P, Jud C, Tobler I, Birchler T, Fontana A (2007) TNF-alpha suppresses the expression of clock genes by interfering with E-box-mediated transcription. Proc Natl Acad Sci U S A 104:12843-12848

Dallmann R, Viola AU, Tarokh L, Cajochen C, Brown SA (2012) The human circadian metabolome. Proc Natl Acad Sci U S A 109:2625-2629

Dallmann R, Brown SA, Gachon F (2014) Chronopharmacology: new insights and therapeutic implications. Annu Rev Pharmacol Toxicol 54:339-361

Damiola F, Le Minh N, Preitner N, Kornmann B, Fleury-Olela F, Schibler U (2000) Restricted feeding uncouples circadian oscillators in peripheral tissues from the central pacemaker in the suprachiasmatic nucleus. Genes Dev 14:2950-2961

Davidson AJ, Castanon-Cervantes O, Leise TL, Molyneux PC, Harrington ME (2009) Visualizing jet lag in the mouse suprachiasmatic nucleus and peripheral circadian timing system. Eur J Neurosci 29:171-180

Eastman CI, Mistlberger RE, Rechtschaffen A (1984) Suprachiasmatic nuclei lesions eliminate circadian temperature and sleep rhythms in the rat. Physiol Behav 32:357-368

Eckel-Mahan KL, Patel VR, Mohney RP, Vignola KS, Baldi P, Sassone-Corsi P (2012) Coordination of the transcriptome and metabolome by the circadian clock. Proc Natl Acad Sci U S A 109:5541-5546

Evans JA, Davidson AJ (2013) Health consequences of circadian disruption in humans and animal models. Prog Mol Biol Transl Sci 119:283-323

Feillet C, Krusche P, Tamanini F, Janssens RC, Downey MJ, Martin P, Teboul M, Saito S, Levi FA, Bretschneider T, van der Horst GT, Delaunay F, Rand DA (2014) Phase locking and multiple oscillating attractors for the coupled mammalian clock and cell cycle. Proc Natl Acad Sci U S A 111:9828-9833

Gamble KL, Berry R, Frank SJ, Young ME (2014) Circadian clock control of endocrine factors. Nat Rev Endocrinol 10:466-475

Gorbacheva VY, Kondratov RV, Zhang R, Cherukuri S, Gudkov AV, Takahashi JS, Antoch MP (2005) Circadian sensitivity to the chemotherapeutic agent cyclophosphamide depends on the 
functional status of the CLOCK/BMAL1 transactivation complex. Proc Natl Acad Sci U S A 102:3407-3412

Innominato PF, Giacchetti S, Bjarnason GA, Focan C, Garufi C, Coudert B, Iacobelli S, Tampellini M, Durando X, Mormont MC, Waterhouse J, Levi FA (2012) Prediction of overall survival through circadian rest-activity monitoring during chemotherapy for metastatic colorectal cancer. Int J Cancer 131:2684-2692

Innominato PF, Roche VP, Palesh OG, Ulusakarya A, Spiegel D, Levi FA (2014) The circadian timing system in clinical oncology. Ann Med 46:191-207

Kowalska E, Ripperger JA, Hoegger DC, Bruegger P, Buch T, Birchler T, Mueller A, Albrecht U, Contaldo C, Brown SA (2013) NONO couples the circadian clock to the cell cycle. Proc Natl Acad Sci U S A 110:1592-1599

Lamont EW, Legault-Coutu D, Cermakian N, Boivin DB (2007) The role of circadian clock genes in mental disorders. Dialogues Clin Neurosci 9:333-342

Maret S, Dorsaz S, Gurcel L, Pradervand S, Petit B, Pfister C, Hagenbuchle O, O'Hara BF, Franken P, Tafti M (2007) Homer1a is a core brain molecular correlate of sleep loss. Proc Natl Acad Sci U S A 104:20090-20095

Martinez-Lozano Sinues P, Tarokh L, Li X, Kohler M, Brown SA, Zenobi R, Dallmann R (2014) Circadian variation of the human metabolome captured by real-time breath analysis. PLoS One 9:e114422

Matsuo T, Yamaguchi S, Mitsui S, Emi A, Shimoda F, Okamura H (2003) Control mechanism of the circadian clock for timing of cell division in vivo. Science 302:255-259

Maury E, Hong HK, Bass J (2014) Circadian disruption in the pathogenesis of metabolic syndrome. Diabetes Metab 40:338-346

Minami Y, Kasukawa T, Kakazu Y, Iigo M, Sugimoto M, Ikeda S, Yasui A, van der Horst GT, Soga T, Ueda HR (2009) Measurement of internal body time by blood metabolomics. Proc Natl Acad Sci U S A 106:9890-9895

Moller-Levet CS, Archer SN, Bucca G, Laing EE, Slak A, Kabiljo R, Lo JC, Santhi N, von Schantz M, Smith CP, Dijk DJ (2013) Effects of insufficient sleep on circadian rhythmicity and expression amplitude of the human blood transcriptome. Proc Natl Acad Sci U S A 110: E1132-E1141

Nagoshi E, Saini C, Bauer C, Laroche T, Naef F, Schibler U (2004) Circadian gene expression in individual fibroblasts: cell-autonomous and self-sustained oscillators pass time to daughter cells. Cell 119:693-705

Panda S, Antoch MP, Miller BH, Su AI, Schook AB, Straume M, Schultz PG, Kay SA, Takahashi JS, Hogenesch JB (2002) Coordinated transcription of key pathways in the mouse by the circadian clock. Cell 109:307-320

Ralph MR, Foster RG, Davis FC, Menaker M (1990) Transplanted suprachiasmatic nucleus determines circadian period. Science 247:975-978

Reddy AB, Karp NA, Maywood ES, Sage EA, Deery M, O’Neill JS, Wong GK, Chesham J, Odell M, Lilley KS, Kyriacou CP, Hastings MH (2006) Circadian orchestration of the hepatic proteome. Curr Biol 16:1107-1115

Robles MS, Cox J, Mann M (2014) In-vivo quantitative proteomics reveals a key contribution of post-transcriptional mechanisms to the circadian regulation of liver metabolism. PLoS Genet 10:e1004047

Stokkan KA, Yamazaki S, Tei H, Sakaki Y, Menaker M (2001) Entrainment of the circadian clock in the liver by feeding. Science 291:490-493

Storch KF, Lipan O, Leykin I, Viswanathan N, Davis FC, Wong WH, Weitz CJ (2002) Extensive and divergent circadian gene expression in liver and heart. Nature 417:78-83

Viswanathan AN, Schernhammer ES (2009) Circulating melatonin and the risk of breast and endometrial cancer in women. Cancer Lett 281:1-7

Vollmers C, Gill S, DiTacchio L, Pulivarthy SR, Le HD, Panda S (2009) Time of feeding and the intrinsic circadian clock drive rhythms in hepatic gene expression. Proc Natl Acad Sci U S A 106:21453-21458 